\title{
Medical termination of pregnancy in the early first trimester
}

\author{
Haitham Hamoda, Gillian M M Flett
}

\begin{abstract}
Surgical abortion using vacuum aspiration or dilatation and curettage has been the method of choice for termination of pregnancy up to 63 days' gestation since the 1960s. Over the last three decades many studies have explored the use of medical methods for inducing abortion at these gestations. Earlier regimens assessed the systemic and intrauterine injection of prostaglandins. This was followed in the 1980s by the introduction of the antiprogesterone, mifepristone. Since its introduction, the uptake of medical abortion has been steadily increasing in countries where it has been available for routine use. Most current clinical protocols require the use of prostaglandins in combination with anti-progesterones or antimetabolites. The safety, efficacy and acceptability of the medical regimen are now well established at all gestations of pregnancy. Provision of medical abortion increases the choice available to women, in particular those wishing to avoid surgery.
\end{abstract}

J Fam Plann Reprod Health Care 2005; 31(1): 10-14 (Accepted 17 October 2004)

\section{Key message points}

- The safety, efficacy and good patient acceptability of medical abortion up to 63 days' gestation is now wel established.

- The provision of medical abortion offers additional choice to women, in particular those wishing to avoid surgery.

- Follow-up provides the opportunity to confirm successful abortion and identify possible complications. This is particularly essential for women who do not expel recognisable products of conception, to exclude risk of failed treatment and continuing pregnancy.

\section{Introduction}

It is estimated that approximately 26 million legal and 20 million illegal abortions are performed annually worldwide, resulting in an abortion rate of 35 per 1000 women aged $15-44$ years. ${ }^{1}$

Surgical abortion by vacuum aspiration or dilatation and curettage has been the method of choice since the 1960s. ${ }^{2}$ However, since the introduction of mifepristone in the 1980s, the uptake of the medical regimen has been steadily increasing in countries where it has been available for routine use, and this has probably been one of the most significant developments in fertility control in recent years. This review explores both the historical aspects and the practical application of the medical regimen in the context of early medical abortion.

Department of Obstetrics and Gynaecology, University of Aberdeen, Aberdeen, UK

H Hamoda, Mrcog, Clinical Research Fellow

G M M Flett, FRCOG, Consultant in Family Planning and

Reproductive Health

Correspondence to: $\mathrm{Dr} \mathrm{H}$ Hamoda, Department of Obstetrics and Gynaecology, University of Aberdeen, Aberdeen Maternity Hospital, Foresterhill, Cornhill Road, Aberdeen AB25 2ZD, UK. Tel: +44 (0) 1224 553582. Fax: +44 (0) 1224684880.

E-mail: ogy262@abdn.ac.uk

\section{Historical background}

Over three decades ago, it was shown that the systemic or intrauterine injection of prostaglandins would induce abortion in over $90 \%$ of women in early pregnancy. 3,4 In 1980, the scientists at Roussel-Uclaf (Romainville, France) discovered a $\mathrm{C} 19$ derivative of norethisterone with a modification at the 11-beta position. This was found to have high affinity for the progesterone receptor. The company's code for this drug was RU38486 (later shortened to RU486) and the generic name, mifepristone. This discovery began a new era in fertility control and has shaped much of our current practice. In 1982, the potential abortifacient effect of mifepristone was demonstrated and the compound was reported to interrupt the menstrual cycle and early pregnancy. ${ }^{5}$ This provoked a wave of publicity and protest from anti-abortion organisations, which has continued to this day. In 1988, France was the first country to license the use of mifepristone in combination with a prostaglandin analogue for termination of pregnancy up to 49 days' gestation. The regimen was licensed in China in the same year and, in 1991, mifepristone was approved by the United Kingdom Licensing Authority for use in Great Britain up to 63 days' gestation. In 1992, mifepristone was approved for use in Sweden, and was eventually approved by the United States Food and Drug Administration for use as an abortifacient in September $2000 .{ }^{6}$

\section{Methods used for medical abortion}

The three main categories of medical abortion are described in the following paragraphs.

\section{Uterotonic compounds (prostaglandins)}

Prostaglandins are naturally occurring fatty acids that are produced by many tissues in the body. Prostaglandins cause uterine contractions and result in softening and dilatation of the cervix.7,8 PGF2 $\alpha$ and PGE2 were first investigated for medical abortion in the 1970s.9 Both cause powerful contractions of the smooth muscle in the myometrium at all stages of pregnancy. This contrasts with the relative uterine insensitivity to oxytocin in early pregnancy.7,10 Prostaglandins, however, also cause contractions in other areas of smooth muscle in the body (e.g. the intestinal wall) and hence may be associated with a high incidence of gastrointestinal side effects. The natural prostaglandins were gradually replaced with the prostaglandin analogues (gemeprost and misoprostol), which are more stable, relatively resistant to metabolism and, therefore, result in more prolonged action. ${ }^{6}$ The initial prostaglandin analogue used in France was sulprostone, a prostaglandin of the PGE2 series, given by intramuscular injection. ${ }^{5}$ However, because of concerns about cardiovascular complications and reports of myocardial infarction, sulprostone was withdrawn from the market and is no longer in use.11 Subsequently, the PGE1 analogues (gemeprost and misoprostol) have been used for medical abortion.

Although abortion can be induced with prostaglandins alone, the dose required results in a high incidence of side effects making prostaglandins unsuitable for use as sole agents to induce abortion. Consequently, most current clinical protocols use prostaglandins in lower doses in combination with antiprogesterones or anti-metabolites. 


\section{Anti-progesterones (mifepristone)}

Progesterone antagonists are synthetic steroids that bind to the progesterone receptor and prevent endogenous progesterone from exerting its effect. ${ }^{12-16}$ Mifepristone binds to the progesterone receptor with an affinity five times greater than that of progesterone, ${ }^{7}$ thus denying endogenous progesterone access to the receptor Mifepristone has some agonist as well as antagonist properties and is also a potent antagonist of cortisol by binding to the glucocorticoid receptor.

The mechanism by which mifepristone seems to act involves an effect on the decidua, myometrium and a ripening effect on the cervix.5,7,13,16 It also prevents progesterone's decidualisation effect on the endometrium. It has been reported that mifepristone results in an increase in uterine contractility $24-36 \mathrm{~h}$ after its administration, and a five-fold increase in the sensitivity to exogenous prostaglandins when administered in the first trimester of pregnancy. $7,10,16$

Mifepristone was initially used as a single agent for abortion. However, the effectiveness was reported to be $60-80 \%$ and the failure rates increased as gestation increased. 5,17 Subsequently, a more effective application was found in combination with prostaglandins, and this forms the mainstay of most current regimens used in clinical practice. ${ }^{18,19}$

\section{Anti-metabolites (methotrexate)}

Methotrexate inhibits dihydrofolate reductase, the enzyme necessary for purine and pyrimidine synthesis. Its effect on pregnancy appears to be predominantly on the rapidly dividing cytotrophoblast. ${ }^{20,21}$ Methotrexate has been shown to be effective for the treatment of gestational trophoblastic disease. ${ }^{22-25}$ However, since 1993 , there has been a renewed interest, particularly in the USA, in the use of methotrexate for medical abortion. ${ }^{6,21}$ Studies have reported the successful use of methotrexate in combination with the prostaglandin analogue, misoprostol. ${ }^{26-28}$ Creinin et al. ${ }^{29}$ reported a randomised trial comparing the administration of misoprostol ( $800 \mu \mathrm{g}$ vaginally) 3 and 7 days after intramuscular methotrexate administration. The study showed that the regimen was more effective when misoprostol was given 7 days (complete abortion 98\%) rather than 3 days (complete abortion 83\%) after methotrexate $(p=0.03)$ and concluded that the protocol would be an effective alternative to surgery or to medical abortion using mifepristone in combination with prostaglandin analogues. The efficacy of the regimen has been reported to be higher when used up to 49 days' gestation and decreased when used at higher gestations. ${ }^{21}$

Methotrexate is potentially teratogenic and there have been several reports of limb reduction defects in fetuses following its use. ${ }^{30}$ The toxicity of methotrexate is dose dependent and can affect rapidly dividing cells in the body including the lining of the gastrointestinal tract, bone marrow and pulmonary interstitium. ${ }^{21}$ This is more likely to occur at doses higher than those used for medical abortion. Nonetheless, serious complications have been reported with low-dose methotrexate. ${ }^{21,31,32} \mathrm{~A}$ further drawback of the regimen is that the induction to abortion interval can be several days or weeks.30 The use of methotrexate in this context has been relatively restricted to places where mifepristone is either unavailable or unaffordable. ${ }^{2}$

Mifepristone in combination with prostaglandin analogues remains the standard regimen used for early medical abortion and will be the focus for the remainder of this review.

\section{Type of prostaglandin}

The most commonly used prostaglandins are the PGE1 analogues, gemeprost and misoprostol. ${ }^{2}$ The conventional prostaglandin analogue used for medical abortion is gemeprost. A $1 \mathrm{mg}$ pessary costs approximately $£ 20$ and is unstable at room temperature. Studies have demonstrated that the PGE1 analogue, misoprostol, is an effective alternative to gemeprost. ${ }^{33}$ Misoprostol is cheap ( $£ 1$ per dose) and, unlike gemeprost, does not require specific storage conditions.

Baird et al. ${ }^{34}$ reported a randomised trial that compared misoprostol $600 \mu \mathrm{g}$ given orally to gemeprost $0.5 \mathrm{mg}$ administered vaginally, both after receiving mifepristone $200 \mathrm{mg}$ orally. The study showed similar efficacy for the two regimens although the continuing pregnancy rates were higher in the misoprostol group and, in particular, for women between 49 and 63 days' gestation. The same group subsequently reported a trial that compared misoprostol $800 \mu \mathrm{g}$ given vaginally to gemeprost $0.5 \mathrm{mg}$ administered vaginally after mifepristone $200 \mathrm{mg}$ orally. ${ }^{33}$ This study showed that the complete abortion rate was higher with misoprostol and the continuing pregnancy rates lower compared to gemeprost. Both differences were statistically significant. The incidence of side effects was similar for women in the two groups. The former study adopted a lower dose of misoprostol $(600 \mu \mathrm{g})$ and used the oral route of administration, which might explain the lower efficacy noted with misoprostol for that group.

\section{Dose}

The Cochrane Database reviewed seven randomised trials comparing mifepristone in doses of 200 to $600 \mathrm{mg} .^{2}$ Of these, four trials were included in a meta-analysis. The review showed similar efficacy for the two regimens and concluded that the dose of mifepristone can be lowered to $200 \mathrm{mg}$ without significantly decreasing efficacy. A multicentre trial conducted by the World Health Organization assessed the effect of further reducing the dose of mifepristone. ${ }^{35}$ This study showed that women receiving $50 \mathrm{mg}$ mifepristone were 1.6 times more likely to experience failed treatment compared to those receiving $200 \mathrm{mg}$. A further study assessed the efficacy of a dose of $100 \mathrm{mg}$ mifepristone and suggested that this may be an adequate dose. ${ }^{36}$ Nonetheless, this was a single-centre, small study and further research is required to evaluate this dose before it can be recommended for use in routine practice.

Studies have reported that the dose of gemeprost could be reduced from 1 to $0.5 \mathrm{mg}$ without a significant reduction in efficacy, while reducing the incidence of prostaglandinrelated side effects. 33,37

Misoprostol has been used in doses of 400-800 $\mu \mathrm{g}$ in combination with mifepristone. In France, where the use of mifepristone was described first, the standard regimen involves the use of mifepristone $600 \mathrm{mg}$ followed by misoprostol $400 \mu \mathrm{g}$ orally in a single dose. 38,39 Two large French trials assessed the regimen and reported success rates of $95-97 \%$ at 49 days' gestation. 38,39 The second French study 39 included women up to 63 days' gestation. The standard regimen was followed by an additional dose of misoprostol $200 \mu \mathrm{g}$ for women who did not abort within $3 \mathrm{~h}$ of the initial dose. The authors concluded that the use of a second dose of misoprostol did not improve efficacy in comparison with historical data from regimens that used only a single dose of misoprostol. Spitz et al. ${ }^{40}$ reported that the efficacy of the medical regimen decreased as gestation increased for women up to 63 days' gestation. However, the regimen used included mifepristone $600 \mathrm{mg}$ followed by a single dose of misoprostol $400 \mu \mathrm{g}$ given orally. Ashok et $a l .41$ reported a review of 2000 women undergoing medical abortion up to 63 days' gestation using mifepristone $200 \mathrm{mg}$ 
followed by a single dose of misoprostol $800 \mu \mathrm{g}$ given vaginally: the complete abortion rate was $97.5 \%$. However, it was noted that efficacy significantly decreased at gestations $\geq 49$ days. Following the review, the regimen was modified to offer a second dose of misoprostol $400 \mu \mathrm{g}$ to women who had not aborted within $4 \mathrm{~h}$ of the initial dose..$^{42}$ There was no difference in the complete abortion rate with the modified regimen (79.9\%). A significant finding, however, was that with the modified two-dose regimen, gestation ceased to have an effect on the overall efficacy and there was a significant reduction in the continuing pregnancy rates. This, nonetheless, was not a randomised study and these findings would need further evaluation, preferably in the context of a randomised trial.

\section{Route of misoprostol administration}

The earlier medical abortion protocols used misoprostol in doses of $400 \mu \mathrm{g}$ administered orally. ${ }^{38,39}$ El-Refaey et al. ${ }^{43}$ reported a randomised trial that compared vaginal to oral administration of misoprostol $800 \mu \mathrm{g}$ following mifepristone $600 \mathrm{mg}$ in the context of medical abortion up to 63 days' gestation and showed superior efficacy and lower side effects with the vaginal route of administration. Zieman et al. ${ }^{44}$ reported on the absorption kinetics of misoprostol with oral and vaginal administration. The study showed that the systemic bioavailability of vaginally administered misoprostol was three times higher than that with the oral route of administration. Peak plasma levels were slightly lower but were achieved more slowly and sustained for up to $4 \mathrm{~h}$. This may explain the higher efficacy and lower side effects noted with vaginal administration compared to the oral route of administration of misoprostol.

It has been suggested that women prefer the oral route of administration and value having additional choice. ${ }^{45-47}$ Studies have since evaluated the feasibility of the sublingual route of misoprostol administration in the context of medical abortion in doses of $600-800 \mu \mathrm{g} .48-52$ The sublingual route was reported to be an effective alternative to the vaginal route of administration with good patient acceptability. The prevalence of prostaglandinrelated side effects, however, was higher. The sublingual route offers additional choice to women, while avoiding the inconvenience of vaginal administration and the first-pass liver effect associated with oral administration. Tang et al. ${ }^{53}$ compared the pharmacokinetics of the sublingual, oral and vaginal routes of misoprostol administration. Sublingual administration achieved the highest peak serum concentrations, while the time to peak concentration was higher for the sublingual and oral routes compared to the vaginal route. The area under the curve was significantly higher with the sublingual route compared to the oral and vaginal routes of administration. This may explain the higher prevalence of side effects noted with sublingual administration. Further research is needed to assess the optimal dose of misoprostol in the context of medical abortion using the sublingual route of administration.

\section{Side effects and complications of medical abortion}

Side effects of the medical regimen include the prostaglandin-related side effects of nausea, vomiting, diarrhoea, abdominal pain, shivering and fever. ${ }^{2,9}$ These side effects are dose-dependent and are more profound with the oral and sublingual routes compared to the vaginal route of administration. 43,48,49,51,52 Excessive bleeding at the time of abortion is rare; however, there is more observed blood loss with medical abortion when compared to surgical abortion. ${ }^{2}$ Blood transfusion has been reported to be required in $0.1-0.2 \%$ of women undergoing medical abortion up to 63 days' gestation. $40,42,54$
Post-abortion genital tract infection of varying degrees of severity, including pelvic inflammatory disease, is estimated to occur in up to $10 \%$ of cases. ${ }^{55}$ The risk is reduced when prophylactic antibiotics are given or when lower genital tract infection has been excluded by bacteriological screening.

Medical regimens carry a small risk of failure to terminate the pregnancy, thus necessitating surgical intervention. In a series of 4132 cases undergoing medical abortion using mifepristone in combination with misoprostol the surgical evacuation rate was $2.3 \% .42$ Indications for surgery included: continuing pregnancy $(0.3 \%)$, missed abortion $(0.3 \%)$ and incomplete abortion (1.6\%). A further series of 3161 women undergoing medical abortion using mifepristone and gemeprost reported a surgical evacuation rate of $3.6 \% .54$ of these, $1.4 \%$ had continuing pregnancy while $2.2 \%$ had incomplete abortion.

Both anti-progesterones and prostaglandins have contraindications to their use including: allergy to mifepristone or prostaglandins, adrenal insufficiency, severe asthma, porphyria, breastfeeding, history of cardiovascular disease and women over the age of 35 years who are heavy smokers. 56

The safety of misoprostol has been documented in doses up to $1600 \mu \mathrm{g}$ per day. ${ }^{57}$ Misoprostol is, however, potentially teratogenic and there have been reports of congenital anomalies associated with its use in the first trimester of pregnancy, and where the pregnancy subsequently continues. These are usually related to vascular disruption possibly related to uterine contractions and include limb defects, skull defects, facial malformations and cranial nerve palsies. ${ }^{9,58}$ Despite the extensive evidence supporting misoprostol's use in this context and its wide uptake, this remains an off-licence application for the product. Women should, therefore, be carefully counselled about this and the potential complications related to its use.

Most women report a sense of relief following abortion while many report complex emotional feelings in the $2-3$ weeks immediately afterwards, which subsequently settle. However, it should be noted that there is an increased risk of psychological morbidity following abortion overall, and it has been reported that about $1 \%$ of women will have a psychiatric admission in the 4 years after abortion. ${ }^{59-64}$

\section{Acceptability}

The provision of medical abortion offers additional choice to women. Reasons given by women in favour of the regimen include: autonomy, more privacy, less invasiveness and greater 'naturalness' than surgery. ${ }^{65}$ Frequently mentioned drawbacks include: abdominal pain, duration of bleeding, number of visits and the time waiting to know if the treatment has been successful. ${ }^{65}$ The percentage of women choosing medical abortion is progressively increasing in countries where it has been in routine use and is about 56\% in France, 59\% in Scotland, 51\% in Sweden, although only $14 \%$ in England and Wales. ${ }^{66-68}$

In a review on the acceptability of medical abortion in early pregnancy, Winikoff 65 reported that in most trials which offered women a choice between medical and surgical methods, $60-70 \%$ of women chose medical methods. There has also been high reported acceptability among women who have undergone medical abortion, with 88-97\% of participants expressing satisfaction. ${ }^{69}$ This assessment was, however, conducted on a self-selected population that had chosen this method for abortion and this needs to be taken into consideration when interpreting the findings. 


\section{Analgesia requirements}

Abdominal pain is one of the most common adverse effects of medical abortion. ${ }^{18,19,40,70-72}$ Analgesia requirements have been reported to be higher in women of younger age, higher gestation and longer induction to abortion interval, while women with a previous live birth(s) were less likely to use analgesia. ${ }^{71,73}$ Analgesia use does not seem to be affected by the route of misoprostol administration used. ${ }^{43,73}$ In a series of 4343 women undergoing medical abortion up to 22 weeks' gestation $72 \%$ used analgesia. Of these, the majority (97\%) used oral analgesia and only $2.3 \%$ required intramuscular opiates. ${ }^{73}$ Westhoff et al. ${ }^{72}$ reported that women undergoing medical abortion and who were given analgesia supplies were more likely to use them compared to those given a prescription. In turn, the latter group had higher analgesia use compared to those asked to use analgesia only as required. The role of pre-emptive analgesia use and its effect on women's acceptability needs to be evaluated in different settings and preferably in the context of a randomised trial.

\section{Home administration of misoprostol}

The provision of medical abortion at home allows the procedure to be carried out in the privacy of a familiar environment and avoids the inconvenience of an additional visit to the hospital. It might also have major cost-saving implications for health service provision.

Studies from the USA have reported high efficacy and acceptability of medical abortion in home settings ${ }^{74-78}$ and home care is becoming the standard in the USA However, home medical abortion is yet to be evaluated in the context of a randomised trial. Despite the reported research from the USA, it would be insufficient to extrapolate these findings to UK settings and, to date, there have been no studies evaluating the feasibility or acceptability of home medical abortion in the UK. A multicentre, questionnaire survey sponsored by the fpa (Family Planning Association) assessed women's views on home administration of misoprostol for medical abortion, and, in particular, their perceived acceptability and perceived ability to cope with the process at home. ${ }^{79} \mathrm{~A}$ total of $71 \%$ of women said there was nothing that happened during abortion in hospital that they would have been unable to cope with at home, while $36 \%$ said they would have opted to undergo home abortion, had that choice been available. However, 64\% indicated that they would prefer to undergo abortion in hospital, suggesting that medical abortion at home is acceptable to women who currently undergo hospital-based medical abortion in UK settings. These findings need to be further evaluated in different settings.

\section{Follow-up}

The main reason for follow-up after medical abortion is to confirm successful abortion and to identify possible complications following the procedure. Abortion is usually confirmed through identifying the products of conception or by carrying out a transvaginal ultrasound of the uterus. Follow-up is usually offered within 2 weeks of abortion. ${ }^{55,80}$ It has been suggested, however, that giving women simple instructions and advice about detecting complications would be a suitable alternative to follow-up, with little evidence that mandatory follow-up visits detect conditions that women could not learn to recognise themselves. ${ }^{81,82}$ Follow-up, however, remains essential for women who do not expel recognisable products of conception, to exclude the risk of failed treatment and continuing pregnancy.

\section{Future directions}

The efficacy, safety and acceptability of the medical regimen for abortion is now well established.40,42,54,83-85 Further research is needed to identify the optimal dose of misoprostol in relation to the different routes of administration, and the role of pre-emptive analgesia and its effect on women's acceptability. Research on the feasibility and acceptability of home medical abortion is also awaited. This could radically change the provision of abortion services and might have important cost implications.

\section{Statements on funding and competing interests}

Funding. None identified.

Competing interests. None identified.

References

1 Henshaw SK, Singh S, Haas T. The incidence of abortion worldwide. Int Fam Plann Perspect 1999; 25(Suppl.): S30-S38. See also http://www.agi-usa.org/pubs/journals/25s3099.html [Accessed 20 August 2004].

2 Kulier R, Gulmezoglu AM, Hofmeyr GJ, Cheng LN, Campana A. Medical methods for first trimester abortion. Cochrane Database Syst Rev 2004(2): CD002855.

3 Karim SM, Filshie GM. Use of prostaglandin E2 for therapeutic abortion. BMJ 1970; 3: 198-200.

4 Karim SM, Filshie GM. Therapeutic abortion using prostaglandin F2alpha. Lancet 1970; 1: 157-159.

5 Murray S, Muse K. Mifepristone and first trimester abortion. Clin Obstet Gynecol 1996; 39: 474-485.

6 Baird DT. Medical abortion in the first trimester. Best Pract Res Clin Obstet Gynaecol 2002; 16: 221-236.

7 Baird DT. Mode of action of medical methods of abortion. J Am Med Womens Assoc 2000; 55(3 Suppl.): 121-126.

8 Tang OS, Ho PC. Medical abortion in the second trimester. Best Pract Res Clin Obstet Gynaecol 2002; 16: 237-246.

9 Chong YS, Su LL, Arulkumaran S. Misoprostol: a quarter century of use, abuse, and creative misuse. Obstet Gynecol Surv 2004; 59 $128-140$.

10 Swahn ML, Bygdeman M. The effect of the antiprogestin RU 486 on uterine contractility and sensitivity to prostaglandin and oxytocin. $\mathrm{Br}$ Obstet Gynaecol 1988; 95: 126-134.

11 Ulmann A, Silvestre L, Chemama L, Rezvani Y, Renault M, Aguillaume $\mathrm{CJ}$, et al. Medical termination of early pregnancy with mifepristone (RU 486) followed by a prostaglandin analogue. Study in 16,369 women. Acta Obstet Gynecol Scand 1992; 71: 278-283.

12 Spitz IM, Croxatto HB, Robbins A. Antiprogestins: mechanism of action and contraceptive potential. Annu Rev Pharmacol Toxicol 1996; 36: $47-81$

13 Robbins A, Spitz IM. Mifepristone: clinical pharmacology. Clin Obstet Gynecol 1996; 39: 436-450.

14 Van Look PF, Bygdeman M. Medical approaches to termination of early pregnancy. Bull WHO 1989; 67: 567-575.

15 Van Look PF, von Hertzen H. Clinical uses of antiprogestogens. Hum Reprod Update 1995; 1: 19-34.

16 Ashok PW, Wagaarachchi PT, Templeton A. The antiprogestogen mifepristone: a review. Curr Med Chem Immunol Endocr Metab Agents 2002; 2: 71-90.

17 Grimes DA, Mishell DR Jr, David HP. A randomized clinical trial of mifepristone (RU486) for induction of delayed menses: efficacy and acceptability. Contraception 1992; 46: 1-10.

18 The efficacy and tolerance of mifepristone and prostaglandin in termination of pregnancy of less than 63 days gestation; UK Multicentre Study - final results. Contraception $1997 ; \mathbf{5 5}$ : 1-5.

19 The efficacy and tolerance of mifepristone and prostaglandin in first trimester termination of pregnancy. UK Multicentre Trial. Br J Obstet Gynaecol 1990; 97: 480-486.

20 Creinin MD, Darney PD. Methotrexate and misoprostol for early abortion. Contraception 1993; 48: 339-348.

21 Creinin MD, Pymar HC. Medical abortion alternatives to mifepristone. J Am Med Womens Assoc 2000; 55(3 Suppl.): 127-132.

22 Khan F, Everard J, Ahmed S, Coleman RE, Aitken M, Hancock BW. Low-risk persistent gestational trophoblastic disease treated with lowdose methotrexate: efficacy, acute and long-term effects. Br J Cancer 2003; 89: 2197-2201

23 Lurain JR. Pharmacotherapy of gestational trophoblastic disease. Expert Opin Pharmacother 2003; 4: 2005-2017.

24 Newlands ES, Paradinas FJ, Fisher RA. Recent advances in gestational trophoblastic disease. Hematol Oncol Clin North Am 1999; 13: 225-244.

25 Schorge JO, Goldstein DP, Bernstein MR, Berkowitz RS. Gestational trophoblastic disease. Curr Treat Options Oncol 2000; 1: 169-175.

26 Creinin MD. Randomized comparison of efficacy, acceptability and cos of medical versus surgical abortion. Contraception 2000; 62: 117-124

27 Creinin MD, Burke AE. Methotrexate and misoprostol for early abortion: a multicenter trial. Acceptability. Contraception 1996; 54: 19-22. 


\section{REVIEW}

28 Creinin MD, Vittinghoff E, Keder L, Darney PD, Tiller G. Methotrexate and misoprostol for early abortion: a multicenter trial. I. Safety and and misoprostol for early abortion: a multice

29 Creinin MD, Vittinghoff E, Galbraith S, Klaisle C. A randomized tria comparing misoprostol three and seven days after methotrexate for early abortion. Am J Obstet Gynecol 1995; 173: 1578-1584.

30 Wiebe ER. Abortion induced with methotrexate and misoprostol: comparison of various protocols. Contraception 1997; 55: 159-163.

31 Horrigan TJ, Fanning J, Marcotte MP. Methotrexate pneumonitis after systemic treatment for ectopic pregnancy. Am J Obstet Gynecol 1997; 176: $714-715$

32 Isaacs JD Jr, McGehee RP, Cowan BD. Life-threatening neutropenia following methotrexate treatment of ectopic pregnancy: a report of two cases. Obstet Gynecol 1996; 88: 694-696.

33 Bartley JB. Double-blind randomized trial of mifepristone in combination with vaginal gemeprost or misoprostol for induction of abortion up to 63 days gestation. Hum Reprod 2001; 16: 2098-2102.

34 Baird DT, Sukcharoen N, Thong KJ. Randomized trial of misoprosto and Cervagem in combination with a reduced dose of mifepristone for induction of abortion. Hum Reprod 1995; 10: 1521-1527.

35 Lowering the doses of mifepristone and gemeprost for early abortion: a randomised controlled trial. World Health Organization Task Force on Post-ovulatory Methods for Fertility Regulation. Br J Obstet Gynaecol 2001; 108: 738-742.

36 Creinin MD, Pymar HC, Schwartz JL. Mifepristone $100 \mathrm{mg}$ in abortion regimens. Obstet Gynecol 2001; 98: 434-439.

37 Rodger MW, Logan AF, Baird DT. Induction of early abortion with mifepristone (RU486) and two different doses of prostaglandin pessary (gemeprost). Contraception 1989; 39: 497-502.

38 Peyron R, Aubeny E, Targosz V, Silvestre L, Renault M, Elkik F, et al. Early termination of pregnancy with mifepristone (RU 486) and the orally active prostaglandin misoprostol. N Engl J Med 1993; 328: 1509-1513.

39 Aubeny E, Peyron R, Turpin CL, Renault M, Targosz V, Silvestre L, et $a l$. Termination of early pregnancy (up to 63 days of amenorrhea) with mifepristone and increasing doses of misoprostol. Int J Fertil Menopausal Stud 1995; 40(Suppl. 2): 85-91.

40 Spitz IM, Bardin CW, Benton L, Robbins A. Early pregnancy termination with mifepristone and misoprostol in the United States. N Engl J Med 1998; 338: 1241-1247.

41 Ashok PW, Penney GC, Flett GM, Templeton A. An effective regimen for early medical abortion: a report of 2000 consecutive cases. Hum Reprod 1998; 13: 2962-2965.

42 Ashok PW, Templeton A, Wagaarachchi PT, Flett GM. Factors affecting the outcome of early medical abortion: a review of 4132 consecutive cases. Br J Obstet Gynaecol 2002; 109: 1281-1289.

43 El Refaey H, Rajasekar D, Abdalla M, Calder L, Templeton A. Induction of abortion with mifepristone (RU 486) and oral or vaginal misoprostol. N Engl J Med 1995; 332: 983-987.

44 Zieman M, Fong SK, Benowitz NL, Banskter D, Darney PD. Absorption kinetics of misoprostol with oral or vaginal administration. Obstet Gynecol 1997; 90: 88-92.

45 Ngai SW, Tang OS, Ho PC. Randomized comparison of vaginal (200 microg every $3 \mathrm{~h}$ ) and oral (400 microg every $3 \mathrm{~h}$ ) misoprostol when combined with mifepristone in termination of second trimester pregnancy. Hum Reprod 2000; 15: 2205-2208.

46 Ho PC, Ngai SW, Liu KL, Wong GC, Lee SW. Vaginal misoprostol compared with oral misoprostol in termination of second-trimester pregnancy. Obstet Gynecol 1997; 90: 735-738.

47 Howie FL, Henshaw RC, Naji SA, Russell IT, Templeton AA. Medical abortion or vacuum aspiration? Two year follow up of a patien preference trial. Br J Obstet Gynaecol 1997; 104: 829-833.

48 Tang OS, Ho PC. Pilot study on the use of sublingual misoprostol for medical abortion. Contraception 2001; 64: 315-317.

49 Tang OS, Miao BY, Lee SWH, Ho PC. Pilot study on the use of repeated doses of sublingual misoprostol in termination of pregnancy up to 12 weeks' gestation: efficacy and acceptability. Hum Reprod 2002; 17: 654-658.

50 Tang OS, Wong KS, Tang LC, Ho PC. Pilot study on the use of repeated doses of misoprostol in termination of pregnancy at less than 9 weeks' of gestation. Adv Contracept 1999; 15: 211-216.

51 Tang OS, Chan CC, Ng EH, Lee SW, Ho PC. A prospective, randomized, placebo-controlled trial on the use of mifepristone with sublingual or vaginal misoprostol for medical abortions of less than weeks' gestation. Hum Reprod 2003; 18: 2315-2318.

52 Hamoda H, Ashok PW, Dow J, Flett GM, Templeton A. A pilot study of mifepristone in combination with sublingual or vaginal misoprostol for medical termination of pregnancy up to 63 days' gestation. Contraception 2003; 68: 335-338.

53 Tang OS, Schweer H, Seyberth HW, Lee SWH, Ho PC. Pharmacokinetics of different routes of administration of misoprostol. Hum Reprod 2002; 17: 332-336.

54 Bartley J, Tong S, Everington D, Baird DT. Parity is a major determinant of success rate in medical abortion: a retrospective analysis of 316 consecutive cases of early medical abortion treated with reduced doses of mifepristone and vaginal gemeprost. Contraception 2000; 62: 297-303.

55 Royal College of Obstetricians and Gynaecologists (RCOG) Clinical Effectiveness Support Unit. The Care of Women Requesting Induced Abortion. London, UK: RCOG Press, 2000.
56 von Hertzen H. Research on regimens for early medical abortion. Am Med Womens Assoc 2000; 55(3 Suppl ): 133-136.

57 Scheepers HCJ, Van Erp EJM, Van den Bergh AS. Use of misoprosto in first and second trimester abortion: a review. Obstet Gynecol Surv 1999; 54: 592-600

58 Orioli IM, Castilla EE. Epidemiological assessment of misoprostol teratogenicity. Br J Obstet Gynaecol 2000; 107: 519-523.

59 Thorp JM Jr, Hartmann KE, Shadigian E. Long-term physical and psychological health consequences of induced abortion: review of the evidence. Obstet Gynecol Surv 2003; 58: 67-79.

60 Reardon DC, Cougle JR. Depression and unintended pregnancy in the National Longitudinal Survey of Youth: a cohort study. BMJ 2002; 324: $151-152$.

61 Reardon DC, Cougle JR, Rue VM, Shuping MW, Coleman PK, Ney PG. Psychiatric admissions of low-income women following abortion and childbirth (see Comment). CMAJ 2003; 168: 1253-1256.

62 Reardon DC, Ney PG, Scheuren F, Cougle J, Coleman PK, Strahan TW. Deaths associated with pregnancy outcome: a record linkage study of low-income women. South Med J 2002; 95: 834-841.

63 Gissler M, Hemminki E, Lonnqvist J. Suicides after pregnancy in Finland, 1987-94: register linkage study. BMJ 1996; 313: 1431-1434.

64 Morgan CL, Evans M, Peters JR. Suicides after pregnancy. Mental health may deteriorate as a direct effect of induced abortion. BMJ 1997; 314: 902 ; author reply $902-903$.

65 Winikoff B. Acceptability of medical abortion in early pregnancy. Fam Plann Perspect 1995; 27: 142-148, 185.

66 Jones RK, Henshaw SK. Mifepristone for early medical abortion: experiences in France, Great Britain and Sweden (Special Report) Perspect Sex Reprod Health 2002; 34: 154-161. See also http://www.agi-usa.org/pubs/journals/3415402.html\#16a [Accessed 20 August 2004].

67 Abortion Statistics for England and Wales 2002. Department of Health Bulletin 2003/23. London, UK: Department of Health, 2003.

68 Information and Statistics Division (ISD). Abortion Statistics in Scotland 2002 - ISD Scotland Health Briefing. Edinburgh, UK: ISD, 2003

69 Newhall EP, Winikoff B. Abortion with mifepristone and misoprostol: regimens, efficacy, acceptability and future directions. Am J Obste Gynecol 2000; 183(Suppl.): S44-S53.

70 Oral mifepristone $600 \mathrm{mg}$ and vaginal gemeprost for mid-trimester induction of abortion. An open multicenter study. UK Multicentre Study Group. Contraception 1997; 56: 361-366.

71 Westhoff C, Dasmahapatra R, Winikoff B, Clarke S. Predictors of analgesia use during supervised medical abortion. The Mifepristone Clinical Trials Group. Contraception 2000; 61: 225-229.

72 Westhoff C, Dasmahapatra R, Schaff E. Analgesia during at-home use of misoprostol as part of a medical abortion regimen. Contraception 2000; 62: 311-314.

73 Hamoda H, Ashok PW, Flett GM, Templeton A. Analgesia requirements and predictors of analgesia use for women undergoing medical abortio up to 22 weeks of gestation. Br J Obstet Gynaecol 2004; 111: 996-1000.

74 Schaff EA, Stadalius LS, Eisinger SH, Franks P. Vaginal misoprosto administered at home after mifepristone (RU486) for abortion. J Fam Pract 1997; 44: 353-360.

75 Schaff EA, Fielding SL, Westhoff C, Ellertson C, Eisinger SH, Stadalius LS, et al. Vaginal misoprostol administered 1, 2, or 3 days after mifepristone for early medical abortion: a randomized trial. JAMA 2000; 284: 1948-1953.

76 Schaff EA, Fielding SL, Eisinger SH, Stadalius LS, Fuller L. Low-dose mifepristone followed by vaginal misoprostol at 48 hours for abortion up to 63 days. Contraception 2000; 61: 41-46.

77 Schaff EA, Eisinger SH, Stadalius LS, Franks P, Gore BZ, Poppema S Low-dose mifepristone $200 \mathrm{mg}$ and vaginal misoprostol for abortion. Contraception 1999; 59: 1-6.

78 Pymar HC, Creinin MD, Schwartz JL. Mifepristone followed on the same day by vaginal misoprostol for early abortion. Contraception 2001; 64: 87-92

79 Hamoda H, Critchley HOD, Paterson K, Guthrie K, Rodger M, Penney GC. The acceptability of home medical abortion to women in UK GC. The acceptability of home medical

80 World Health Organization (WHO). Safe abortion: technical and policy guidance for health systems. Geneva, Switzerland: WHO, 2003. http://www.who.int/reproductive-health [Accessed 20 August 2004].

81 Grossman D, Ellertson C, Grimes DA, Walker D. Routine follow-up visits after first-trimester induced abortion. Obstet Gynecol 2004; 103: 738-745.

82 Grimes DA. Medical abortion in early pregnancy: a review of the evidence. Obstet Gynecol 1997; 89(5 Pt 1): 790-796.

83 Henshaw RC, Naji SA, Russell IT, Templeton AA. A comparison of medical abortion (using mifepristone and gemeprost) with surgical vacuum aspiration: efficacy and early medical sequelae. Hum Reprod vacuum aspiration:

84 Henshaw RC, Naji SA, Russell IT, Templeton AA. Comparison of medical abortion with surgical vacuum aspiration: women's preference and acceptability of treatment. BMJ 1993; 307: 714-717.

85 Henshaw R, Naji S, Russell I, Templeton A. Psychological responses following medical abortion (using mifepristone and gemeprost) an surgical vacuum aspiration. A patient-centered, partially randomised prospective study. Acta Obstet Gynecol Scand 1994; 73: 812-818. 